\title{
Emotional and behavioral problems of 9- 18-year-old girls and its relationship to menarche age
}

\author{
Naeimeh Tayebi ${ }^{1}$, Shahrzad Yektatalab² and Marzieh Akbarzadeh ${ }^{3 *}$
}

\begin{abstract}
Background: Adolescence is associated with rapid changes in behavioral patterns which affect the functioning of the person in adulthood. The purpose of this research was to study the emotional and behavioral problems of 918-year-old girls and their relationship to menarche age. This cross-sectional study was done on girls aged 9-18 years old in Shiraz city. A cluster sampling method was used to select about 2000 students in 2015. Then, a questionnaire including demographic characteristics and strengths and difficulties (SDQ) was completed for each of them. The SPSS software was used to analyze the collected data via descriptive statistics and chi-square tests.

Results: Among the 2000 tested samples, the highest mean and standard deviation (4.2 \pm 2.25$)$ were related to emotional symptoms. Most of them (960 individuals $=48 \%$ ) scored abnormally. The mean and standard deviation was $15.61 \pm 5.89$, and the highest value was 33. The highest mean and standard deviation (16.69 \pm 5.4$)$ ranged from 17 to 18 years old in 289 subjects. There was a significant relationship between the age of menarche and emotional and behavioral problems $(p=0.001)$. Most individuals (638 subjects) $(46 \%)$ had abnormal emotional and behavioral problems in the menarche age of 11-12 years old.
\end{abstract}

Conclusion: Emotional symptoms were the most common emotional-behavioral problems of adolescents. There was a significant relationship between the menarche age and emotional and behavioral problems. It is necessary to be familiar with the problems of adolescent girls during adolescence and the way to deal with their problems.

Keywords: Menarche age, Behavioral problems, Emotional problems, Female adolescents, Psychological problems

\section{Background}

Adolescence is one of the most important periods of life, and in fact, this stage is considered to be a kind childhood to adulthood transition. This intermediate phase is accompanied by important physical, psychological, and social changes in addition to rapid changes in behavioral patterns that affect the performance of the individual during adulthood [1]. According to the World Health Organization (WHO), people between 10 and 19 years old are considered to be adolescents [2]. Based on the 2006 census, $21.8 \%$ of Iran's population is between 10

\footnotetext{
*Correspondence: marzieh.akhbar@gmail.com

${ }^{3}$ Maternal-Fetal Medicine Research Center, Department of Midwifery, School of Nursing and Midwifery, Shiraz University of Medical Sciences, Shiraz, Iran Full list of author information is available at the end of the article
}

and 19 years old [3]. In adolescence, the basis of many behaviors affecting the health and lifestyle of individuals is formed [4]. Most attitudes and behaviors formed during this period determine the habits of a healthy lifestyle during adulthood [5].

The results of studies conducted by Friedman and colleagues in 2001, Kimm and colleagues in 2002, and O'Loughlin and colleagues in 2003 have shown that risk factors, both behavioral and biological, associated with non-communicable diseases are formed during childhood and adolescence, and they are stable until adolescence [6-8]. Behaviors and lifestyles of this age have a profound effect on major illnesses in the future, especially in today's world where the pattern of illnesses has changed and illnesses caused by the unhealthy lifestyle 
patterns have been passed to the top of the list of the causes of death [4].

Ericsson considered adolescence as a period of identity vs. role confusion. Given that identity is the unity that exists in the three biological, social, and psychological systems, when such unity is not achieved, adolescents' relationships and behaviors are disturbed. Holling and colleagues in 2007, in their study on German teenagers, reported that $11.9 \%$ of adolescents needed mental health services due to behavioral problems [9]. The most frequent psychiatric disorders in childhood and adolescence are anxiety disorders (up to $31.9 \%$ ), behavior disorders (16.3-19.1\%), substance use disorders (8.3$11.4 \%)$, emotional disorders (3.7-14.3\%), hyperkinetic disorders (2.2-8.6\%), and aggressive anti-social disorders $(2.1-7.6 \%)$ [10]. Personal problems usually occur when they face new conditions of puberty and identity crisis. In other words, the disability of the adolescent in adapting to the new conditions leads to the emergence of behavioral problems. The results of several studies have shown that girls show their problems as internal behaviors such as isolation, physical symptoms, depression, and anxiety [11]. Also, some studies have shown that emotional and psychological problems of adolescents increase with age [12].

One of the most critical periods in a woman's life is adolescence which leads to the onset of menstruation. About $70-90 \%$ of women undergo various physical and mental changes before or after menstruation bleeding or at its onset, which is called premenstrual tension or molimina [13]. Actually, emotional imbalance and instability are the most prominent features of adolescence. Sensitivities and emotions caused by irritability, which are the prominent features of this period, are often due to changes in the endocrine system, level of hormonal secretions, and type of education and training of adolescents in the past that totally make up the emotional state of the adolescent [14]. Evaluation of the psychiatric problems of children in the community and finding the sufferers are the first steps in promoting the level of mental health in this age group. Because no extensive study has been conducted in this area in our society, the researchers decided to conduct a study to investigate emotional and behavioral problems of 9-18-year-old girls and its relationship to menarche age

\section{Methods}

This analytical, epidemiological, and cross-sectional study was performed in 2014-2015. All female students in the primary, guidance, and high school were included in the study across all four districts of Shiraz city. By considering the previous studies [15] and statistics experts, the obtained sample size was 1625 female students based on the formula and confidence level of 95\%. By considering the probability of the sample size fall, 2000 were estimated as the sample size.

$$
\begin{aligned}
& n=\frac{Z^{2} p q}{d^{2}} \\
& \mathrm{P} 1=0.35, \mathrm{P} 2=0.60, \mathrm{P} 3=0.05,1-\alpha=0.95, d=0 / 01, \\
& q=1-p
\end{aligned}
$$

The inclusion criteria were girls between 9 and 18 years old, willing to participate in the study, and completed the written informed consent with no background of taking medication (except anti-allergic and pain killers -3 months prior to the study) or chronic physical and mental illness. The aim of this study was to make adolescents completely healthy. Antibiotics are important and may be used to treat chronic diseases that affect the hormonal cycle and the onset of menarche. The exclusion criterion was suffering from any hormonal diseases such as growth hormone, thyroid gland, and adrenal glands disorders; diabetes; skeletal, muscular, and neurological disorders; and chronic diseases like asthma. Awareness of diseases has been the selfreporting of girls and their parents. Those who had experienced a crisis or stressful event who were willing to withdraw from the study or their parents requested to withdraw their children from the study were excluded. First, the cluster sampling method was used, and 6 to 8 schools were selected randomly through convenience sampling for the selection of 500 students at each educational level. In the present study, the researcher asked the departments to complete demographic and SDQ questionnaires after obtaining permission from related authorities, examining the inclusion and exclusion criteria of the study, and explaining the study objectives. The scientific validity of the questionnaire was evaluated via content validity. Moreover, it was assured that the information about all subjects would remain confidential. The study instruments had two parts: (1) personal information about menarche (including menarche age and demographic information) and (2) SDQ questionnaire. After studying the reference textbooks and various sources, the researchers selected Robert Goodman's Questionnaire with Cronbach's alpha of 0.73. This questionnaire contained 25 questions about the behavioral and emotional problems of children from the viewpoint of parents and teachers with three categories of response (not true, somewhat true, and certainly true). The minimum and maximum total score ranged from 0 to 40 . The questionnaire had five indicators (emotional problems, overactive problems, behavioral problems, and communicational problems with peers and appropriate social behaviors). This questionnaire has been validated by Dr. Tehranidoust in the Iranian children's community $[16,17]$. The collected data were analyzed through the 
SPSS software (version 21) using descriptive statistics and a chi-square test.

\section{Results}

Table 1 shows the status of the indicator of emotional and behavioral problems in female students. The highest mean and standard deviation $(2.35 \pm 4.2)$ were related to emotional symptoms, and the lowest mean and standard deviation $(1.93 \pm 3.33)$ were related to the peers' problems. Table 2 shows the emotional and behavioral problems of female students. Most of the subjects (960 individuals) (48\%) had abnormal scores, and the lowest of them (337 subjects) (16.9\%) scored as intermediate. The mean and standard deviation was $15.61 \pm 5.89$. The highest value was 33 , and the lowest was zero. Table 3 shows the emotional and behavioral problems in terms of age in female students. The highest mean and standard deviation (16.69 \pm 5.4$)$ were in the range of 17-18 years old girls (289 subjects), and the lowest mean and standard deviation $(13.82 \pm 5.8)$ were in the range of 11-12 years old girls ( 73 subjects). Table 4 shows the relationship between menarche age and emotional and behavioral problems in female students. The chi-square test between the menarche age and emotional and behavioral problems showed that there was a significant relationship between the two variables at the confidence level of $95 \%$. The test value was equal to 22.17 with a significance level of $p=0.001$. Most of the subjects (57\%) had abnormal behavioral and emotional problems at the menarche age of $15-16$ years old.

\section{Ethical considerations}

The local Ethics Committee of Shiraz University of Medical Sciences approved the study protocol (grant number 7173). Permissions were also received through the authorities in the schools. Written informed consent was collected from all the participants. The confidentiality of all participants' personal information was assured. Furthermore, they were free to withdraw from the study at any time.

Table 1 Mean and standard deviation of the index of emotional and behavioral problems questionnaire in girls

\begin{tabular}{llll}
\hline Index & Mean \pm SD & Min & Max \\
\hline Emotional Symptoms Score & $4.2 \pm 2.35$ & 0 & 10 \\
Peer Problems Score & $3.41 \pm 2.03$ & 0 & 10 \\
Hyperactivity/Inattention Score & $4.44 \pm 2.1$ & 0 & 10 \\
Conduct Problems Score & $3.33 \pm 1.93$ & 0 & 10 \\
Behavior Score Prosocial & $6.96 \pm 2.09$ & 0 & 10 \\
Total & $15.4 \pm 5.96$ & 0 & 33 \\
\hline
\end{tabular}

\section{Discussion}

Epidemiological studies show that 5-10\% of children and adolescents suffer from emotional and behavioral problems, which are among the most common psychiatric disorders for this age group [18]. Emotional and behavioral problems are associated with suffering and disturbances in the daily life of the affected person, his/her family, and among the relatives. These problems were associated with an increased risk of substance abuse, depression, and impaired social and emotional functioning during adolescence and early adulthood [18-21]. Therefore, emotional and behavioral problems in childhood should be identified and treated as soon as possible.

The standard deviation and mean of the total score of the questionnaire's strengths and difficulties in the sample were $15.61 \pm 5.89$. The value was reported as 5.5 in Muris et al.'s (2003) study in the Netherlands, 5.1 in the study by Klasem et al. (2000) in Germany, 10.85 in Smedje et al.'s (1999) study in Sweden, 11.4 in Goodman et al.'s (1998) study in England, and 10.05 in Tehranidoust et al.'s (2008) study in Tehran $(17,22,25)$. The reason mentioned for the difference in the total score of the strengths and difficulties is the difference in the real prevalence of problems in different countries and probably different mean ages of the study subjects [22]. Therefore, in this study group, the age group of 9-18 years old, the highest mean score was in the range of 17-18 years old with an average of 16.69 .

Nasiri et al. carried out a study to determine the prevalence of mental health disorders in primary school children in Boushehr city (2006-2007). A total of 2350 SDQ questionnaires were distributed randomly in urban and rural primary schools. In this study, 946 (49.3\%) subjects had an abnormal score similar to that of the present study in which 960 (48\%) subjects had an abnormal score [22].

A comparison of the indicators obtained from the SDQ questionnaire in the present study showed that the highest mean was related to the dimension of appropriate social behaviors; this is consistent with the studies of Tehranidoust et al. and Arabgol et al. The lowest mean was related to the dimension of problems with peers, while in Tehranidoust and Arabgol's studies, the lowest mean was related to behavioral problems $[17,23]$.

Latif Nezhad et al. conducted a study with the aim of comparing emotional and behavioral problems and depression in two groups of girls before and after menarche in Mashhad city. In this case-control study, 320 healthy high school children aged 11 to 15 years old (140 girls in the pre-menarche period and 140 in the postmenarche period) who did not have emotional and behavioral problems were selected through multistage sampling from 18 high schools in Mashhad. The results showed no significant difference in the behavioral and 
Table 2 Distribution of emotional and behavioral problems in the student city of Shiraz

\begin{tabular}{llll}
\hline Emotional and behavioral problems & $\boldsymbol{N}(\%)$ & Mean \pm SD & Min \\
\hline Normal & $703(35.2)$ & & \\
Borderline & $337(16.9)$ & $15.61 \pm 5.89$ & 0 \\
Abnormal & $960(48)$ & & 33 \\
Total & $2000(100)$ & & \\
\hline
\end{tabular}

emotional problems of the girls in the post-menarche period in comparison with those in the pre-menarche period. However, in this study, the relationship between emotional and behavioral problems and menopause age was statistically significant. Most of them (638 subjects) (46\%) had emotional and behavioral problems at the menarche age of 11-12 years [24]. However, in Tehranidoust et al.'s study, the scores of the SDQ questionnaire score were not significantly correlated to age [17]. Moreover, in another study by Sanders on Japanese families living in Australia (2007), 50 families were evaluated in two case and control groups. Then, a significant difference was observed in the dimensions of parenthood, parenting, and adolescent behavioral problems at the end of the intervention. However, there was no significant difference in anxiety, stress, and depression [25]. Grant et al.'s (2003) study concluded that stressful events, such as the conflict in the family, have a significant role in the expansion of emotional and behavioral problems in children and adolescents [26].

Garnefski et al.'s study (2005) also investigated children and adolescents aged 12 to 18 years in the Netherlands among the general population. They found that the scores of people with emotional and behavioral problems were significantly higher than those of the control group and the group with conditions of behavioral problems in terms of cognitive coping strategies as self-blame and rumination [27]. In a case-control study in Birjand, it was found that the mean of emotional and behavioral problems and aggression was significantly higher in divorce children than non-divorced children [28]. Cognitive-behavioral therapy was strongly supported as an effective treatment for emotional and behavioral problems in children [29]. However, the vast majority of children and adolescents with emotional and

Table 3 Distribution of emotional and behavioral problems by age in the student city of Shiraz

\begin{tabular}{lllll}
\hline Age & Number & Mean \pm SD & Min & Max \\
\hline $9-10$ & 500 & $15.68 \pm 5.7$ & 2 & 32 \\
$11-12$ & 73 & $13.82 \pm 5.8$ & 3 & 31 \\
$13-14$ & 926 & $14.72 \pm 6.29$ & 0 & 33 \\
$15-16$ & 211 & $16.37 \pm 5.1$ & 1 & 31 \\
$17-18$ & 289 & $16.69 \pm 5.4$ & 1 & 28 \\
\hline
\end{tabular}

behavioral problems do not receive evidence-based psychological treatment [30,31].

Turner et al. showed that adolescents who were in the warm, intimate, adaptive, communicative, and supportive environment of their family could control the negative effects of stress on their health [32]. In adolescence, the role of parents and their ability to communicate positively and constructively with their adolescent is very critical. Studies showed that warm and protective family relationships were predictive of the positive correlation between children and adolescents and are considered as protective factors against emotional and behavioral problems in adolescence [33].

Van et al. (2012) investigated the impact of social skills training programs for children aged 7 to 13 years on emotional and behavioral problems. The results showed that social skills training caused positive changes in children's emotional and behavioral problems [34]. Chen (2006) and Spence's (2003) study on students at risk of behavioral and emotional disturbances indicated that social skills training, which included modeling, feedback, and encouragement in case of proper performance and role-plays, led to an increase in their social adequacy $[35,36]$.

Senik showed that training social skills led to increased social interaction and interpersonal relationships followed by increased indicators of psychological well-being, income-earning, and consequently increased quality of their life [37]. A meta-analysis study showed that two thirds of adolescents who were at risk of behavioral and emotional disorders but received social skills training were improved compared with the control group [38, 39].

Generally, the review of the studies conducted on social skills training shows that 25 years after the beginning of research in this field, the researchers make an attempt to train these skills in order to make people acquire, maintain, and publicize the skills to overcome or reduce their behavioral and emotional problems $[38,40]$.

It should be noted that mental disorders may activate the corticotropin-releasing hormone from the nervous system following an increase in cortisol and prolactin, which leads to menstrual symptoms [41, 42]. In addition to the effects of hormones released on the quality of life, these mental disorders may lead to suicide, addiction, early sexual experience, depression in adulthood, crimes, loss of education, low self-esteem, and its consequences, eventually leading to occupational, family, and social 
Table 4 The relationship between the age of menarche emotional and behavioral problems in the student city of Shiraz

\begin{tabular}{|c|c|c|c|c|c|c|c|}
\hline Emotional and behavioral problems & $9-10, N(\%)$ & $11-12, N(\%)$ & $13-14, N(\%)$ & $15-16, N(\%)$ & Total, $N(\%)$ & Chi-square & Significance level \\
\hline Normal & $36(50.7)$ & $284(38.8)$ & $200(35.6)$ & $3(14.3)$ & $523(37.7)$ & & \\
\hline Borderline & $3(4.2)$ & $134(18.3)$ & $82(14.6)$ & $6(28.6)$ & $225(16.3)$ & & \\
\hline Abnormal & $32(45.1)$ & $314(42.9)$ & $280(49.8)$ & $12(57.1)$ & $638(46)$ & 22.17 & 0.001 \\
\hline Total & $71(100)$ & $732(100)$ & $562(100)$ & $21(100)$ & $1386(100)$ & & \\
\hline
\end{tabular}

disorders $[43,44]$. The prevalence of these mental disorders in the premenstrual period is rare. Gender differences show that during puberty, these disorders increase with a steep slope and are more common among the girls who are more vulnerable to various psychological factors so that the ratio of the girls' psychological condition in these disorders compared to boys is $1 / 1 / 3$ [45].

In explaining these results, it can be mentioned that life skills are like a behavior change-based approach that can make a balance between knowledge, attitude, and skills and can increase stress-coping skills, self-esteem, and individual control in different situations. The adolescence period is a critical stage in the course of which the foundation of adulthood can be set for a person [46]. This period is associated with significant physical and mental changes, and the lack of awareness of adolescents in this period may lead to inaccurate performance and adverse outcomes. Training can reduce many of the problems and crises of that period. Therefore, since it is important to know how to enter the process of adolescence and how to overcome its ups and downs by adolescents, families should get acquainted with the time and trends of menarche and factors affecting it in order to provide their children with the right decisions in a timely manner [47]. Training issues, especially support of the family, can reduce the stresses and menstrual disorders of the adolescent girls [48], given that the main aim of this project was to study the prevalence of menarche, early and late menarche. Therefore, the factors affecting adolescents' psychological problems have not been fully evaluated. Other factors affecting psychological problems have been proposed as a design limitation in the article.

Another factor in the development of emotional and behavioral problems are socioeconomic status; a possible clue could be related to the type of school and area of residence. Further research is suggested to confirm the relationship between environmental factors and menarche onset age, development of secondary sexual characteristics, perception of puberty or physical maturity compared to peers, and the rate of puberty in different racial-ethnic groups so that the existing contradictions are resolved. Besides, interest in environmental factors that have influenced the onset of puberty has increased significantly over the past three decades. However, despite extensive studies, how environmental factors affect the first menstrual period is largely unclear.

\section{Conclusion}

Emotional symptoms were the most emotional and behavioral problems in adolescents. There was a significant relationship between the menarche age and emotional and behavioral problems. Therefore, the attention of the parents and family plays a significant role in the behavior of adolescents. According to the results of this study, it is suggested that some strategies should be developed in the form of educational programs based on the problems and psychological characteristics of the girls in order to prepare themselves for coping with adolescent conditions. It is necessary to develop mental health programs appropriate for adolescent age based on their problems and educational conditions. Besides, one of the goals set by the World Health Organization in 2020 is to promote a healthy lifestyle in the community. Accordingly, countries should put on their agenda strategies that are effective in improving individual and social life and the factors that lead to unhealthy lifestyles (such as poor physical activity, poor nutrition, and substance abuse). Therefore, in health care systems, it is necessary to pay serious attention to behavioral approaches and risk factors simultaneously with clinical examination. Among these, due to the decrease in the age of developing harmful behaviors and due to the sensitivity of adolescents and the formation of intellectual, ideological, social, and emotional values, this group should be prioritized.

\section{Abbreviations}

SDQ: Strengths and difficulties; WHO: World Health Organization

\section{Acknowledgements}

The authors would like to thank Shiraz University of Medical Sciences, Shiraz, Iran, and also the Center for Development of Clinical Research of Nemazee Hospital and Dr. Nasrin Shokrpour for the editorial assistance.

\section{Authors' contributions}

NT and MA: concept and design. SY and MA: data collection and interpretation of the data. NT and SY: performing of the study and writing of the draft. All authors read and approved the study.

\section{Funding}

This work was supported by the Shiraz University of Medical Sciences, Shiraz, Iran.

Availability of data and materials

The datasets used and/or analyzed during the current study are available from the corresponding author on reasonable request. 


\section{Ethics approval and consent to participate}

The local Ethics Committee of Shiraz University of Medical Sciences approved the study protocol (number 7173). Permissions were also received through the authorities in the schools. Written informed consent was collected from all the participants and the parent or legal guardian of participants under 16 years old.

\section{Consent for publication}

Not applicable

\section{Competing interests}

The authors declare no conflict of interest.

\section{Author details}

'Department of Midwifery, School of Nursing and Midwifery, Bam University of Medical Sciences, Bam, Iran. ${ }^{2}$ syychiatric Nursing Department, School of Nursing and Midwifery, Shiraz University of Medical Sciences, Shiraz, Iran. ${ }^{3}$ Maternal-Fetal Medicine Research Center, Department of Midwifery, School of Nursing and Midwifery, Shiraz University of Medical Sciences, Shiraz, Iran.

Received: 12 August 2020 Accepted: 9 November 2020

Published online: 01 December 2020

\section{References}

1. Klein JD, Wilson KM (2002) Delivering quality care: adolescents' discussion of health risks with their providers. J Adolesc Health. 30(3):190-195

2. Alikhani S (2014) A profile of unintentional injuries among Iranian adolescents: findings from the first Health Behavior in School-Aged Children Survey. Int J School Health. 1(2):1-5

3. Iran SCo. Iran Statistical Yearbook 2003: Population by age and sex, 1996 Census 2011 Available from http://www.sci.org.ir/portal/faces/public/ census85.

4. Amir Khani M, Motlagh M, Sedaght M, Namazy R, Ardalan G, Haghdost A. Health status, risky health behaviors of students based on academic year 2006-7. Isfahan: Isfahan University of Medical Sciences. 2008;3(7):24.

5. Neumark-Sztainer D (2006) Eating among teens: do family mealtimes make a difference for adolescents' nutrition? New Dir Child Adolesc Dev. 111:91105

6. Freedman DS, Khan LK, Dietz WH, Srinivasan SR, Berenson GS (2001) Relationship of childhood obesity to coronary heart disease risk factors in adulthood: the Bogalusa Heart Study. Pediatrics. 108(3):712-718

7. Kimm SY, Glynn NW, Kriska AM, Barton BA, Kronsberg SS, Daniels SR et al (2002) Decline in physical activity in black girls and white girls during adolescence. N Engl J Med. 347(10):709-715

8. O'Loughlin JL, Tarasuk J (2003) Smoking, physical activity, and diet in North American youth: where are we at? Can J Public Health. 94(1):27-30

9. Holling H, Erhar T, Ravens S, Schlak R (2007) Behavioral problems in children and adolescence. J Psychol Gesundheitsschutz SO (S-6)(S-6):784-793

10. Fuchs M, Bosch A, Hausmann A, Steiner H (2013) «The child is father of the man» - review of literature on epidemiology in child and adolescent psychiatry. Z Kinder Jugendpsychiatr Psychother. 41(1):45-55 quiz 6-7

11. Helstela L, Sourander A (2001) Self-reported competence and emotional and behavioral problems in a sample of Finnish adolescents. Nord $J$ Psychiatry. 55(6):381-385

12. Liu X, Sun Z, Neiderhiser JM, Uchiyama M, Okawa M, Rogan W (2001) Behavioral and emotional problems in Chinese adolescents: parent and teacher reports. J Am Acad Child Adolesc Psychiatry. 40(7):828-836

13. Gharekhani P, Sadatiyan S (2002) The main protests and treatment of women, 3rd edn. Noredanesh Publications, Tehran

14. Helm Seresht P, Del Pishe A (1998) The community of health nursing. Publication of chehr, Tehran

15. Muris P, Meesters C, van den Berg F (2003) The Strengths and Difficulties Questionnaire (SDQ)--further evidence for its reliability and validity in a community sample of Dutch children and adolescents. Eur Child Adolesc Psychiatry. 12(1):1-8

16. Cury CR, Golfeto JH (2003) Strengths and Difficulties Questionnaire (SDQ): a study of school children in Ribeirão Preto. Braz J Psychiatry. 25(3):139-145

17. Tehranidoust M, Shahrivar Z, Pakbaz B, Rezaie A, Ahmadi F (2006) Validity of Persian version of Strength and Difficulties Questionnaire. J Adv Cogn Sci. 33(4):33-39
18. Thapar A, Pine D, Leckman JF, Scott S, Snowling MJ, Taylor EA. Rutter's child and adolescent psychiatry Wiley. 2017.

19. Costello EJ, Angold A, Keeler GP (1999) Adolescent outcomes of childhood disorders: the consequences of severity and impairment. J Am Acad Child Adolesc Psychiatry. 38(2):121-128

20. Fichter MM, Quadflieg N, Fischer UC, Kohlboeck G (2010) Twenty-five-year course and outcome in anxiety and depression in the Upper Bavarian Longitudinal Community Study. Acta Psychiatr Scand. 122(1):75-85

21. Ginsburg GS, La Greca AM, Silverman WK (1998) Social anxiety in children with anxiety disorders: relation with social and emotional functioning. J Abnorm Child Psychol. 26(3):175-185

22. Nasiri M, Faghih A, Yazdan Parast A, Motamed N (2007) Mental health disorders among school children in Bushehr city

23. Arabgol F, Mahmoodigharii J, Hakimshoshtare M (2007) The effect of life skills training program on the performance of students in fourth grade. $J$ Adv Cogn Sci. 7(3):51-57

24. Latifnejad Rodsari R, Rastegari Moghaddam A, Sahebi A (2010) Evaluation of anxiety and depression in girls around puberty. Suppl Congress Epidemiol. 5:134

25. Sumargi A, Sofronoff K, Morawska A (2015) A randomized-controlled trial of the Triple P-Positive Parenting Program Seminar Series with Indonesian parents. Child Psychiatry Hum Dev. 46(5):749-761

26. Grant KE, Compas BE, Stuhlmacher AF, Thurm AE, McMahon SD, Halpert JA (2003) Stressors and child and adolescent psychopathology: moving from markers to mechanisms of risk. Psychol Bull. 129(3):447-466

27. Garnefski N, Kraaij V, van Etten M (2005) Specificity of relations between adolescents' cognitive emotion regulation strategies and internalizing and externalizing psychopathology. Journal of adolescence. 28(5):619-631

28. Kaheni S, Hasan AM (2000) Competitive of anxiety \& stress in teenagers (12-19 years) in families of divorced and none divorced. Birjand Med J. 7:39-41

29. James AC, James G, Cowdrey FA, Soler A, Choke A (2013) Cognitive behavioural therapy for anxiety disorders in children and adolescents. Cochrane Database Syst Rev. 6:CD004690

30. Chavira DA, Stein MB, Bailey K, Stein MT (2004) Child anxiety in primary care: prevalent but untreated. Depress Anxiety. 20(4):155-164

31. Costello EJ, He JP, Sampson NA, Kessler RC, Merikangas KR (2014) Services for adolescents with psychiatric disorders: 12-month data from the National Comorbidity Survey-Adolescent. Psychiatr Serv. 65(3):359-366

32. Turner NE, Macdonald J, Somerset M (2008) Life skills, mathematical reasoning and critical thinking: a curriculum for the prevention of problem gambling. Journal of Gambling Studies. 24(3):367-380

33. Sanders MR, Woolley M (2005) The relationship between maternal self-efficacy and parenting practices: implications for parent training. Child 31(1):65-73

34. Van Vugt E, Deković M, Prinzie P, Stams G, Asscher J (2013) Evaluation of a group-based social skills training for children with problem behavior. Child Youth Serv Rev. 35(1):162-167

35. Chen K (2006) Social skills intervention for students with emotional/ behavioral disorders: a literature review from the American Perspective. Educ Res Rev. 1(4):143-149

36. Spence SH (2003) Social skills training with children and young people: theory, evidence and practice. Child Adolesc Ment Health. 8(2):84-96

37. Senik C (2005) Income distribution and well-being: what can we learn from subjective data? J Econ Surv. 19(1):43-63

38. Cook CR, Gresham FM, Kern L, Barreras RB, Thornton S, Crews SD (2008) Social skills training for secondary students with emotional and/or behavioral disorders: a review and analysis of the meta-analytic literature. J Emotional Behav Disord. 16(3):131-144

39. Gresham FM, Cook CR, Crews SD, Kern L (2004) Social skills training for children and youth with emotional and behavioral disorders: validity considerations and future directions. Behav Disord. 30(1):32-46

40. Gresham FM (2002) Teaching social skills to high-risk children and youth: preventive and remedial strategies

41. Gibbs RS, Danforth DN, Karlan BY, Haney AF (2018) Danforth's Obstetr Gynecol 10th ed. USA: Lippincott Williams and Wilkins

42. Lee CA, Kadir R, Kouides P (2009) Inherited bleeding disorders in women, 1st edn. Wiley- Blackwell, London, pp 40-90

43. Dehghan-nayeri N, Adib-Hajbaghery M (2011) Effects of progressive relaxation on anxiety and quality of life in female students: a nonrandomized controlled trial. Complement Ther Med. 19:194-200 [PubMed]

44. Sooky Z, Sharifi KH, Tagharrobi Z, Akbari H, Mesdaghinia A (2010) Depression prevalence and its correlation with the psychosocial need 
satisfaction among Kashan high-school female students. Feyz J Kashan Univ Med Sci Autumn. 14:256-263

45. Costello J, Erkanli A, Angold A (2006) Is there an epidemic of child or adolescent depression? J Child Psychol Psychiatry. 47:1263-1271

46. Basso O, Weinberg CR, D'Aloisio AA, Sandler DP (2019) Mother's age at delivery and daughters' risk of preeclampsia. Paediatr Perinat Epidemiol. 33(2):129-136

47. Tayebi N, Yazdznpanahi Z, Yektatalab S, Akbarzadeh M, Zare N. Pattern of menarche age (normal, early and late) and its relationship with some demographic characteristics in girls and their parents. Int J Adolesc Med Health. 2016;30(3)

48. Akbarzadeh M, Tayebi N, Abootalebi M (2017) The relationship between age at menarche and primary dysmenorrhea in female students of shiraz schools. Shiraz E-Med J. 18(9):e14520

\section{Publisher's Note}

Springer Nature remains neutral with regard to jurisdictional claims in published maps and institutional affiliations.

\section{Submit your manuscript to a SpringerOpen ${ }^{\circ}$ journal and benefit from:}

- Convenient online submission

- Rigorous peer review

- Open access: articles freely available online

High visibility within the field

- Retaining the copyright to your article

Submit your next manuscript at $\boldsymbol{\nabla}$ springeropen.com 